\title{
Global perspectives on higher education and lifelong learning
}

\author{
By Maria Slowey and Hans G. Schuetze (eds). Routledge, London, 2012, \\ 300 pp. ISBN 978-0-415-67507-9 (hbk), ISBN 978-0-203-12249-5 (e-book)
}

\section{Julia Preece}

Published online: 18 January 2014

(C) Springer Science+Business Media Dordrecht and UNESCO Institute for Lifelong Learning 2014

This book is an international review of the interface between higher education and lifelong learning in 14 countries. It is a follow-up to previous reviews produced in 1987 and 2000 respectively. This publication includes two additional chapters from emerging economy countries (Brazil and South Africa) and one each from Mexico and Portugal. The chapters look at systems and structures for increasing participation in university education using lifelong learning's organising principles of access and flexibility for teaching and learning. This review reflects changes in the way higher education is being financed and managed since the onset of the new millennium.

The editors' general observation, not surprisingly, is that whilst there has been considerable expansion and growth in diversity for higher education across all contexts with differing levels of progress, the pressures of performativity have often mitigated against part-time provision and sensitivity to learner diversity. Similarly, they observe that information technology advances have not been exploited as much as one might have expected.

The overall focus of the book is on how institutions cater for the complex nature of lifelong learners in terms of age, motivation for study and equity in the context of expanding technologies and pathways to higher learning. The chapters provide a snapshot of how their respective countries address two lifelong learning policy tensions which are, on the one hand, underpinned by social justice concerns for equity and, on the other, dominated by a neo liberal agenda for human capital development. The book is divided into six parts, mostly reflecting the geographical chapter groupings.

In Part one, an introductory chapter summarises global developments since the 1970s, and offers various guiding principles for lifelong learning, with a typology of lifelong learners and the nature of provision flexibility. Part two consists of six

\footnotetext{
J. Preece $(\bowtie)$

Centre for Adult Education, University of KwaZulu-Natal, Pietermaritzburg, South Africa e-mail: julia.preece@glasgow.ac.uk
} 
chapters from European countries. These chapters all reflect a "post-Bologna" era whereby, amongst other things, university degrees were rationalised with a view to facilitating credit transfer and a normative programme of undergraduate study that would be completed within three or four years. In some cases, such as in Austria, this produced fairly major changes in governance and general expansion of access, though with less impact on opportunities for lifelong learners. In other cases, for instance in Germany, there is now more permeability between vocational and academic subjects, and qualifications frameworks provide some scaffolding opportunities for qualification equivalences. The chapter on Ireland argues that pockets of innovation remain but that lifelong learning should be perceived as more than a flexible system of entry. The chapter on Portugal reminds us that historical contexts still influence participation levels. A concern across many chapters, for example Sweden, is that higher education is becoming vocationalised, thus deflecting from its original purpose for critical thinking. This issue is reflected in the UK chapter which describes the demise of the university extra-mural tradition and a general decline in adult participation in university education.

Part three comprises chapters eight to ten; covering Canada, the United States and Mexico. These are vast countries with federal and/or independent states. Their systems are complex, introducing a new theme of aboriginal discrepancies and colonial overlays which also emerge in subsequent chapters. Both Canada and the United States (chapters eight and ten) provide a patchwork of diversity and policies that scaffold their varied systems. So on the one hand, there are many opportunities for lifelong and life-wide learning, but the complexity is such that only the experienced lifelong learner would be able to exploit those opportunities. Mexico (chapter nine) highlights its context of extreme inequalities and few formal policies for lifelong learning, resulting in fragmented examples of good practice.

Part four (chapters eleven to thirteen) presents findings from Australia, Japan and New Zealand - the Pacific region. Australia, another vast continent, reflects its transition phases from being largely British-influenced to developing closer ties with its Pacific rim. Sandwiched within those transitions there are milestone policies for higher education expansion, blurring of boundaries between different tertiary systems and efforts to address an ever-increasing range of diverse social groups, with "mixed success" (p. 205), particularly for aboriginal groups. New Zealand (chapter thirteen), a much smaller country, shares similar historical and ideological trends but in a context of increasing economic uncertainty for the widening participation agenda. Chapter twelve discusses Japan's very different cultural heritage, whereby lifelong learning was originally a cultural pursuit and largely separate from the higher education sector, though increasing pressures of the knowledge-based society are drawing universities into this discourse.

The final two chapters, in Part five, represent two middle-income BRICS countries, ${ }^{1}$ South Africa and Brazil. Both countries are responding to their own histories of emerging economic growth as well as, in South Africa's case, the legacy of a highly unequal apartheid regime. South Africa's policy of redress is firmly

\footnotetext{
1 The acronym BRICS stands for a group of five emerging economies, namely Brazil, Russia, India, China and South Africa.
} 
articulated in lifelong learning policy, but focuses on the majority, young population as well as resource constraints for expansion, quality and equity measures. In Brazil's case, in a context which does not have a formal lifelong learning policy, the author's comments are refreshingly embedded in a concern for values-based curricula which is barely mentioned across the other chapters.

The book serves an important purpose in that it maps the territory for higher education responses to the lifelong learning discourse, showing both contextspecific differences as well as highlighting some similarities. There are some interesting social purpose observations that flicker across the dominant stories of human capital policies and trends, systems and structures for enabling credit accumulation and transfer, along with the occasional special initiatives to redress past inequalities of participation in spite of performativity challenges for competitiveness and internationalisation. Those observations include the occasional reference to the need to think of lifelong learning as something more than systems and structures (Ireland), and the relevance of content that addresses social issues such as racism (Brazil). But these are rare moments. I am left wondering how we can shift the agenda to one that encourages institutions to think about how higher education can contribute to a more holistic perspective, perhaps reflecting the International Council of Adult Education's recent drive to promote the "education we need for the world we want". 